\title{
Serviços de Acolhimento Institucional infanto-juvenil: desafios históricos e possibilidades de atuação do psicólogo
}

\author{
Institutional Shelter Services for child and youth: historical challenges and possibilities of \\ psychologist's performance \\ Carine Moreira Estevan ${ }^{+*}$, Letícia Verciano Baltor ${ }^{\ddagger}$, Roberta Barbosa da Silva ${ }^{\S}$
}

Como citar esse artigo. ESTEVAN, C.M.; BALTOR, L.V.; DA SILVA, R.B. Serviços de Acolhimento Institucional infanto-juvenil: desafios históricos e possibilidades de atuação do psicólogo. Revista Mosaico, v.11, n.1, p. 54-62, 2020 .

\begin{abstract}
Resumo
O presente artigo teve como objetivo problematizar a relação entre acolhimento institucional, pobreza e negligência familiar, além de realizar um apontamento dos desafios e contribuições da Psicologia nos serviços de acolhimento. Sendo assim, foi utilizada uma revisão da literatura especializada, abarcando o caráter plural da institucionalização infanto-juvenil no Brasil e sua construção histórica. Nesse sentido, indica-se a produção da família pobre como negligente e a ineficiência do Estado mediante às políticas públicas e sociais na garantia de direitos deste público. Discorre-se ainda, sobre as atuações possíveis do profissional de Psicologia diante do processo de institucionalização. Durante a produção do presente artigo, foi possível identificar o papel político do (a) Psicólogo (a) frente à rede de atendimento e garantias de direito, além da sua atuação referente à ressignificação de histórias e sua função como facilitador do protagonismo infanto-juvenil.

Palavras-chave: Institucionalização Infanto-juvenil, Negligência Familiar, Psicologia nos Serviços de Acolhimento.
\end{abstract}

\begin{abstract}
This article aims to questioning the relationship between institutional shelter care, poverty and family negligence, besides make an appointment of the challenges and contributions of psychology in shelter services. Therefore, a review of the specialized literature was used, covering the plural character of the institutionalization of child and youth in Brazil and its historical construction. In this sense, it indicates the production of poor families as negligent and the inefficiency of the State through public and social policies on rights guarantees of the public. It also discusses the possible performance of the psychology professional in the face of the institutionalization process. During the production of this article, it was possible to identify the political role of the Psychologist (a) across the service network and guarantees of rights, in addition to his role regarding the reframing of stories and his role as a facilitator of child and youth protagonism.
\end{abstract}

Keywords: Institutional shelter for Child and youth, Family neglect, Psychology in Shelter services

\section{Introdução}

O presente artigo teve como objetivo problematizar a relação entre acolhimento institucional e pobreza sob o pretexto de negligência familiar. Tal realidade é orientada por uma lógica elitista na qual se opera a culpabilização dessas famílias, obtendo-se o rompimento de vínculos e o deslocamento das crianças e adolescentes de um lugar até então conhecido para uma instituição, gerando diversos impactos em sua vida nos mais amplos aspectos, sejam afetivos, emocionais, cognitivos, sociais e/ou psíquicos.

Portanto, foi realizada uma revisão da literatura especializada, a fim de alcançar uma percepção plural da situação de acolhimento. Por conseguinte, valeu-se de artigos científicos encontrados nas bases de dados:
Scielo, PEPSIC e Google Acadêmico, bem como teses e livros relacionados à temática. Dessa forma, utilizaramse como palavras-chave: "institucionalização infantojuvenil"; "negligência familiar" e " psicologia nos serviços de acolhimento".

Este estudo se faz altamente relevante, visto que o acolhimento apresenta diversas repercussões na vida das crianças, adolescentes e das famílias envolvidas, impondo a eles adaptação a um contexto inesperado, requerendo dos profissionais de Psicologia um aparato teórico e técnico para atuar nessas instituições de acolhimento, onde diversos agenciamentos são demandados.

Sendo assim, levamos em conta certos questionamentos para conduzir este trabalho: $\mathrm{O}$ que leva uma criança e um adolescente a serem acolhidos? Quais as alterações em sua vida e que espaços são estes onde

\footnotetext{
Afiliação dos autores:

${ }^{\dagger}$ Acadêmica de Psicologia pela Universidade de Vassouras, Curso de Psicologia, Universidade de Vassouras, Vassouras, Rio de Janeiro, Brasil

* Acadêmica de Psicologia pela Universidade de Vassouras, Curso de Psicologia, Universidade de Vassouras, Vassouras, Rio de Janeiro, Brasil

$\S$ Mestre em Psicologia pela UFF, Curso de Psicologia, Universidade de Vassouras, Vassouras, Rio de Janeiro, Brasil
}

* Email de correspondência: carinnestevan@hotmail.com 
eles são institucionalizados? E a Psicologia, qual será o seu papel e a forma de atuação diante da imposição destas mudanças, a uma "nova" realidade?

Diante disso, o artigo foi dividido em quatro tópicos. Em um primeiro momento, realizou-se um percurso histórico do acolhimento no Brasil, posteriormente, objetivou-se elucidar o surgimento do termo "negligente" fomentando a desqualificação da família pobre, em seguida, verificou-se os possíveis desafios e impactos dessa medida na vida das crianças e adolescentes, e, por último, apresentou-se o papel do psicólogo nesse processo e suas possibilidades de atuação.

\section{Uma percepção histórica do acolhimento institucional no Brasil}

Para entender a realidade do processo de acolhimento institucional nos dias atuais, é necessário dialogar a respeito da construção política e histórica dos direitos das crianças e adolescentes desde as primeiras práticas de institucionalização no Brasil. Diante disso, será feita uma revisão literária acerca do tema com o intuito de observar a "preocupação" e transformação com o acolhimento infanto-juvenil. Será realizada, portanto, uma breve retrospectiva começando pela época do Brasil colônia (séc. XVI e XVII), quando os colonizadores encontrando resistência dos nativos à cultura europeia, recorreram aos jesuítas como estratégia com o objetivo de investir em crianças indígenas consideradas de mais fácil acesso com a missão de catequizá-las. Assim, esses "meninos da terra" e também crianças órfãs rejeitadas que chegavam de Portugal durante este período, participavam de reuniões para aprender a ler, escrever e "adquirir bons costumes" por meio de um modelo disciplinar ríspido nas instituições denominadas "Casas dos Muchachos" (BAPTISTA, 2006; ALMEIDA, 2013).

Segundo Baptista (2006), Ferreira e Rojas (2013), no século XVIII a "Roda dos expostos" constituiu a principal política do período colonial ao período republicano, tratava-se de um cilindro giratório que deixava no anonimato a identidade dos genitores que abandonavam seus filhos. Esse novo sistema era uma forma de manifestar indícios de tolerância da sociedade com essas crianças, filhos de pecadores, pobres e rejeitadas, principalmente com os filhos de escravos negros que engrossavam a população de crianças órfãs e abandonadas, sobretudo, depois da Lei do ventre Livre. Após a abolição dos escravos, a miséria era o principal motivo para a institucionalização das crianças, e a responsabilidade de garantir os cuidados e proteção cabia, prioritariamente, às Santas Casas de Misericórdia. Salienta-se que, antes da existência da Roda dos Expostos, essas crianças eram submetidas a diversos perigos e tinham poucas chances de sobrevivência, já que eram abandonadas nas ruas e entregues nas casas de desconhecidos (ALMEIDA, 2013). É importante ressaltar que esse mecanismo "Roda dos Expostos" foi extinto somente em meados de 1948 (ASSIS; DINIZ; SOUZA, 2018).

Segundo Daros e Paludo (2012), no ano de 1822, o Brasil deixa de ser Colônia, tornando-se uma nação livre de Portugal, assumindo sua responsabilidade diante das questões do país. Durante esse período, destaca-se o aumento da circulação de crianças e adolescentes pobres nos centros urbanos. Diante dessa situação, o governo adotou como estratégia a criação de escolas de aprendizes de marinheiro e de aprendizes de guerra para receberem os meninos. Já as meninas que se encontravam na mesma situação de pobreza eram encaminhadas para instituições religiosas destinadas somente a mulheres. É importante destacar que não era discutida a economia do país como produtora desse mal, e toda responsabilidade pela situação dessas crianças recaía apenas sobre suas famílias (RIZZINI; RIZZINI, 2004).

Com a Proclamação da República, foram instituídas pela autonomia constitucional novas políticas institucionais e de aprendizagem para crianças brasileiras. Em 1923, foi criado o primeiro Juizado de Menores, instância voltada ao controle da população infanto-juvenil. Além disso, em 1924 constituiu-se o Conselho de Assistência e Proteção aos Menores e o Abrigo de Menores, resultando no primeiro Código de Menores em 1927 (ASSIS; DINIZ; SOUZA, 2018); (ALMEIDA, 2013). A criação de um órgão voltado à infância (Juizado de Menores), bem como de uma legislação específica (Código de Menores, 1927), objetivava "atentar-se melhor" a este segmento social, controlando-o e normatizando-o segundo valores submetidos pela burguesia, minimizando possíveis condutas desviantes (COIMBRA; AYRES; NASCIMENTO, 2008).

De acordo com França (2004) e Assis, Diniz e Souza (2018), a fim de respaldar as instituições de acolhimento por intermédio do Poder jurídico, foram criadas técnicas para apoiar os serviços de acolhimento através de uma abordagem predominantemente médico-jurídica. Nessa época, surge o termo "Menor", passando a ser uma nomenclatura jurídica e social, que categoriza e classifica a infância e adolescência pobre, diferenciando-as de outros segmentos infantis da época. Tratava-se, então, de uma forma de negar e segregar suas existências. A respeito disso, Marino (2013) reforça que se encontra no cerne do termo "menor" uma marca atemporal da subjetivação do adolescente e da criança em situação de pobreza.

Ainda, para Assis, Diniz e Souza (2018), em 1964, através da Lei 4.513, surgiu a Política de Bem-Estar do Menor, uma proposta assistencialista da FUNABEM (Fundação Nacional de Bem-Estar do Menor), mas 
que, apesar dos discursos avançados, mantinhamse práticas de institucionalização das décadas antecedentes, verificando a substituição do aspecto que antes via o menino pobre como ameaça social pelo modelo assistencialista, que passa a percebê-lo como carente, e, portanto, sendo mais bem assistidos nesses internatos (FERREIRA; BITTENCOURT, 2009). Em contrapartida, surgem os primeiros movimentos sociais em defesa dos direitos das crianças e adolescentes pobres, desempenhando práticas alternativas através de novas perspectivas nacionais de atendimento.

Em 1979, foi reformulado o Código de Menores (Lei 6.697), mas este não fazia grande alteração às diretrizes normativas e do poder centralizador do juiz. Ele apenas reafirmou o termo "menor", que vinha sendo usado desde o Código de Menores de 1927, uma vez que ambos trouxeram em seu cerne a concepção de que apenas os "menores" - crianças e adolescentes pobres e "delinquentes"- deveriam ser tutelados pelo Estado (SANTOS, 2004). No entanto, com a justificativa de tentar solucionar a injustiça social que há anos vinha sendo praticada contra esses jovens, o Estado brasileiro, através da FUNABEM, criou novas políticas, aspirando características que se aproximassem a um modelo familiar. Contudo, o atendimento dado pela FUNABEM permaneceu com caráter punitivo e de isolamento social, já que essas instituições estatais tinham como princípio a doutrina da segurança nacional em consonância com o regime militar. Esta lógica meramente punitiva e segregadora que perpassava essa instituição, é vislumbrada em notícias de violência, fugas e até mesmo morte nas chamadas unidades de "recuperação" do "menor" (ASSIS; DINIZ; SOUZA, 2018).

A partir de 1980, a cultura institucional que até então vigorava no país começa a ser questionada quanto à sua eficácia acerca da institucionalização de crianças e adolescentes. Concomitantemente, ocorreram as discussões preparatórias para a Convenção do Direito da Criança aprovada na Assembleia Geral da ONU em 1989. Tal fato desemboca na inclusão do Art. 227 da atual Constituição Federal de 1988, a conhecida Constituição Cidadã, que considera as crianças e adolescentes como sujeitos de direitos e deveres, possibilitando a criação do Estatuto da Criança e Adolescente - ECA (Lei 8.069/1990): um conjunto de normas que dispõe sobre a proteção integral de crianças e adolescentes. Em decorrência da publicação do ECA, a FUNABEM foi extinta (SANTOS, 2013).

De acordo com Orionte e Souza (2005), até a aprovação do ECA, a criança não era reconhecida como cidadão pleno com direitos, mas como um sujeito incompleto e incapaz, cujas necessidades deveriam ser expressas pela voz de um adulto, e essa invisibilidade perpassava diferentes instituições, desde a família, escola e serviços de acolhimento.

Dessa forma, logo após a sua implantação ocorreram mudanças sobre as internações do público infanto-juvenil, visto que, de acordo com o Art. 101 do ECA:

$\mathrm{O}$ acolhimento institucional e o acolhimento familiar são medidas provisórias e excepcionais, utilizáveis como forma de transição para reintegração familiar ou, não sendo esta possível, para colocação em família substituta, não implicando privação de liberdade. (BRASIL, 1990).

No entanto, Nascimento (2012) aponta que, apesar desta legislação, o que se verifica, na maioria das vezes, é a ultrapassagem do tempo de permanência das crianças acolhidas, já que consta no ECA em seu Art.19 $\S 2^{\circ}$ que não poderá se prolongar por mais de dois anos, salvo comprovada a necessidade fundamentada pela autoridade judiciária.

No entanto, o que chama atenção sobre essa realidade, atualmente, são as crianças e adolescentes que vivenciam essa circunstância, pois ainda são, em sua maioria, as pobres, isto é, verifica-se uma repetição acerca do perfil dos acolhidos aparentemente baseados em uma política de proteção que age sobre uma perspectiva cultural excludente (NASCIMENTO, 2012), contrariando, desse modo, o estipulado pelo Art. 23 do ECA: "a falta ou a carência de recursos materiais não constitui motivo suficiente para a perda ou suspensão do poder familiar" (BRASIL, 1990).

Ainda, Arantes (2012), baseada no estudo de Pinheiro (2006), nos atenta sobre as diversas representações de crianças abordadas no debate da Constituinte: Em oposição à criança como sujeito de direitos, tinha a criança alvo do assistencialismo, controle, disciplinamento e repressão. Ou seja, por mais que as letras da lei legitimassem as crianças como portadoras de direitos, não abonou, de fato, a representação das crianças e adolescentes pobres como perigosos.

\section{O novo estatuto atribuído às famílias em situação de pobreza: $O$ surgimento do termo "negligente"}

Considerando a importância de colocar em análise algumas práticas que vêm se repetindo como verdades absolutas e inquestionáveis e sobre as alterações trazidas por essa nova legislação (ECA, 1990), a qual não garantiu totalmente a modificação das práticas a respeito da família e da infância pobre, verificam-se diversos estudos que apontam para as desigualdades sociais no Brasil contendo uma base histórica de segregação desse público (SOUZA, 2018).

Ainda, segundo Souza (2018), a família pobre, que antes sofria com problemas socioeconômicos, hoje ganha um novo estatuto, a de "negligente", pois o discurso para acolhimento não é mais o da falta de 
condições materiais para o cuidado da prole, e sim de desrespeito aos direitos fundamentais à pessoa humana, uma nova forma de violência e risco social. Nesse sentido, observa-se uma naturalização da institucionalização que contribui para reafirmar a noção de que recolhimento de crianças e adolescentes é mais adequado do que a permanência em suas famílias pobres.

Nascimento (2012), em seus estudos, traz que o acolhimento institucional se dá quando os responsáveis não conseguem suprir as necessidades de criação dos filhos, ainda mais em um contexto neoliberal, no qual os discursos/práticas individualizam questões sociais, desconsiderando o Estado em suas atribuições de prover serviços básicos à população, isto é, no cenário capitalista, ainda se verifica a culpabilização das famílias pobres que não condizem com os padrões e normas socialmente impostas como adequadas. Dessa forma, a negligência surge como substituta da pobreza, embasando o motivo para o acolhimento institucional.

Nesse sentido, Oliveira e Silva (2019), utilizandose dos dados divulgados pelo Ministério Público do Estado do Rio de Janeiro no Módulo Criança e Adolescente - MCA, apresentam os índices de acolhimento institucional em todo o Estado, constatando que, desde 2008 até o ano de 2017, a negligência é indicada como o maior motivo dos acolhimentos.

$\mathrm{O}$ pretexto para o acolhimento englobado nos discursos de incompetência familiar, devido à falta de condições financeiras, tal como nos antigos Códigos de Menores, configura a principal razão para a desqualificação dessas famílias pobres e para produção de uma subjetividade que as considera incapazes para o cuidado dos filhos. E essa negligência, muitas vezes citada como justificativa do acolhimento, tem uma perspectiva semelhante à violência que intencionalmente causa danos, e que, portanto, legitima uma intervenção técnica e estatal, pois torna-se mais fácil criminalizar a família e individualizar a violência, deixando de fora as relações de poder que levam a isso (NASCIMENTO, 2012).

Nascimento, Rotenberg e Costa (2015) ao problematizarem a concepção de negligência, realizam um questionamento sobre os modelos de cuidado valorizados que orientam diversas práticas relacionadas ao discurso de omissão de responsáveis, definindo os casos considerados de negligência.

Assim, na constatação de que a maioria das crianças e adolescentes são acolhidos sob o pretexto de negligência familiar, será que, realmente, se tratam de crianças abandonadas por seus pais ou de famílias abandonadas pelo Estado e pela sociedade? A negligência, então, poderia estar relacionada a múltiplos determinantes, entre os quais, a ineficiência do Estado em garantir os direitos fundamentais da população?

Diante dessa situação de desigualdade social, na qual famílias que não possuem recursos financeiros para subsidiar o desenvolvimento psicossocial de seus filhos não devem ser rotuladas como negligentes, pois a família inteira está comprometida, assim, tal violência alcança não apenas os filhos, mas os demais membros da família (OLIVEIRA; SILVA, 2019).

Para Souza (2018), deve-se considerar o agravamento da situação de precariedade social do país, resultando no aumento da exclusão e de desigualdade entre as famílias, fazendo com que os serviços de acolhimento passem a ocupar o lugar deixado pela escassez de programas que deveriam acolher esses sujeitos em situação de fragilidade social. Dessa forma, o acolhimento passa a ser uma política valorizada e, muitas vezes, não pensada como última medida a ser utilizada, assim como previsto em lei, ou seja, quando todas as outras possibilidades de reintegração à família já tiverem sido esgotadas. Ainda para este autor, se hoje a criança é considerada como cidadã de direitos que devem ser assegurados, sua família pode vir a deixar de ser. Elas passam a ser compreendidas como se não se aplicassem o suficiente para garantir o sustento de seus filhos, e esse problema passa a ser individualizado.

\section{Os serviços de acolhimento: Desafios e aspirações diante da nova realidade}

Quando todas as alternativas se encontram esgotadas e o acolhimento torna-se inevitável, é importante refletir se as instituições atendem as exigências preconizadas pelo ECA no que diz respeito ao favorecimento do seu desenvolvimento não só físico, mas também emocional.

Embora, comojá visto, oArt. 101 do ECA enfatize que o acolhimento institucional seja uma medida de caráter provisório, a realidade encontrada em muitas instituições mostra que a situação do acolhido pode não ser temporária e, desse modo, o ambiente institucional deve ser ajustado às propostas do Estatuto da Criança e Adolescente, fornecendo condições adequadas para subsidiar a estadia dessas crianças pelo tempo que precisar (FERREIRA; ROJAS, 2013).

Portanto, a casa de acolhimento, sendo a instituição responsável por essas crianças que sofreram algum tipo de violência, tem como função priorizálas. Assim, suas unidades devem estar localizadas em bairros residenciais para que elas possam desfrutar dos serviços externos disponíveis, como ensino regular, profissionalizante, atividades culturais e de lazer, possibilitando a construção de vínculos sociais para além dos arredores da instituição (ASSIS; DINIZ; SOUZA, 2018). Também deverá ser respeitado o Art. 90 do ECA, que define que "as entidades de atendimentos são responsáveis pela manutenção das próprias unidades, assim como pelo planejamento e 
execução de programas de proteção e socioeducativos destinados a criança e adolescentes" (BRASIL, 1990). Assim, essas instituições deverão cumprir suas tarefas visando o que é melhor para o público infanto-juvenil. Ocorrendo o descumprimento dessa norma, essas entidades poderão ser responsabilizadas, pois com a suspensão do poder familiar elas se tornam legalmente responsáveis pela tutela dos acolhidos durante sua permanência na instituição.

Apesar de muito utilizado, o termo "abrigo", atualmente, foi substituído por Unidade de Acolhimento ou Acolhimento Institucional, pois deverá apresentar um ambiente acolhedor, protetor, personalizado e de pequenos grupos. Suas atividades devem possibilitar que as crianças e adolescentes experimentem vivências semelhantes às vividas no contexto familiar e comunitário e, com isso, a maioria dos acolhimentos realiza atendimentos misto, pois no ECA, Art. 92, inciso $\mathrm{V}$, há previsão para a não separação de irmãos. Com isso, é importante compreender a infância como uma elaboração social e a criança como um ser cultural, que vive e se transforma a partir de suas experiências, estando em constante construção. Portanto, compreende-se que a constituição de um indivíduo enquanto sujeito está intimamente relacionada também com a interação social, que colaboram para seu desenvolvimento, por isso é importante que a instituição ofereça uma estrutura adequada para o desenvolvimento socioafetivo diante de um momento difícil de suas vidas (PALAGANA, 2001).

Diante dessa nova realidade, a criança vai experimentar, além do afastamento familiar, a distância de tudo que the era conhecido, como brinquedos, amigos, hábitos, contato com a comunidade, entre outros aspectos que as construíram até ali. Portanto, a situação de acolhimento implica múltiplos rompimentos, ou seja, a necessidade de elaborar diversos lutos (TINOCO; FRANCO, 2011). Dessa forma, quando se vivencia isto adequadamente, é possível construir novos significados, vínculos, e até recuperar os que estavam rompidos devido ao tempo em que ficaram separados, permitindo uma continuidade saudável e satisfatória.

Em suas pesquisas, Gulassa e Lopez (2010) apontam que, enquanto as crianças e adolescentes estiverem nos serviços de acolhimento, os dispositivos instituídos pelo ECAdeverão ser cumpridos, tanto pelos responsáveis da Instituição como pela equipe técnica, por meio de programas que atenderão seus direitos. Assim, quando ocorre o afastamento da família, e a criança ou adolescente chegam à instituição de acolhimento, a forma como são acolhidos e o cuidado que recebem influencia na construção de possibilidades, na conquista de vínculos e autonomia e, portanto, configura o início do processo em relação ao seu futuro. Nesse sentido, é importante que os técnicos inseridos nos serviços de acolhimento conheçam bem as crianças e adolescentes, considerando as particularidades de cada um deles.

Ao contrário do que pensa o senso comum, o Levantamento Nacional dos Abrigos, realizado pelo IPEA/Conanda, no ano de 2003, destacou que a maioria das crianças e dos adolescentes que vivem nessas instituições não são órfãs, elas possuem famílias, e grande parte mantém algum vínculo, e o que se destacou como a principal causa para o acolhimento foi a condição financeira, notando-se que os fatores socioeconômicos dificultam o retorno à família (FERREIRA e BITTENCOURT, 2009).

Ao que se refere a esta nova realidade, cabe ainda examinar o sofrimento causado por múltiplos fatores oriundos do processo de separação e mudança de ambiente físico, uma vez que passam a conviver com pessoas, até então, desconhecidas, podendo, diante desse contexto, terem a autoestima abalada ou até mesmo um processo de isolamento social durante o acolhimento. Dessa forma, torna-se necessário garantir espaços de boa qualidade para esses jovens se expressarem e sonharem, proporcionando que eles restabeleçam sua história (ALTOÉ, 2009).

De acordo com Assis, Diniz e Souza (2018), apesar de estar instituído na lei, algumas instituições de acolhimento ainda não oferecem características que se assemelham a um ambiente residencial, como também não garantem a preservação da singularidade das crianças e adolescentes, como, por exemplo, a posse de objetos pessoais, roupas ou sapatos particulares. Muitas vezes, as crianças usam o que têm disponível, sendo na maioria dos vestuários frutos de doação, podendo ser rasgados e de tamanho diferente.

Outro ponto crucial é refletir acerca da capacidade institucional em auxiliar a criança e adolescente a obter sentimento de confiança, autonomia e pertencimento a algum grupo, preparando-os para construir sua história com perspectivas futuras. Dessa forma, é importante que a instituição de acolhimento siga a lei, proporcionando ao público infanto-juvenil condições para sobrevivência após sua saída da instituição, assim como possibilidades em relação ao novo.

Desse modo, quando a criança e adolescente entram nos serviços de acolhimento, deverá ocorrer de imediato um trabalho focado na sua aceitação, apoio, segurança e também experiência, disponibilizandolhes ferramentas que auxiliem a compreender sobre o mundo e, assim, possibilitar pensar sobre seu futuro. Contudo, cabe ressaltar que este espaço não tem como objetivo substituir o convívio familiar, mas sim oferecer compreensão, permitindo que eles consigam vivenciar seus vínculos afetivos sem uma relação de dependência 
e, para isso, é importante agir de forma franca com a criança, visando propiciar um possível retorno à vida familiar e comunitária de maneira adequada e digna (GUARÁ, 2006).

Cabe aos educadores construir estratégias para ensinar às crianças e adolescentes sobre sua real situação, consolidando a instituição como um local de proteção e resgate de vínculos, descobrindo novos modos de vida. Assim, esse espaço deverá proporcionar atividades que permitam explorar alegria, diminuição da tensão, descontração e comunicação para expressar seus medos e anseios. A equipe deve fazer com que essas crianças e adolescentes acreditem na sua capacidade de construir algo novo e elaborar projetos, desta forma, o trabalho da equipe responsável pelo reforço dos vínculos familiares e comunitários ocorrerá através de projetos socioeducativos, buscando o melhor desenvolvimento diante das possibilidades futuras. Esse exercício trata-se de um compromisso efetivo com cada sujeito institucionalizado que é acolhido e se depara com um lugar estranho e até hostil. Assim, é importante investir na potencialidade do sujeito na superação de seus conflitos, não deixando de considerar que a própria institucionalização provoca uma ruptura dos laços e lugares conhecidos, podendo deixar marcas doloridas, ocasionando sofrimento, por isso é importante que um educador presente afaste a ideia de um novo abandono (GUARÁ, 2006).

Segundo Ferreira e Rojas (2013), independentemente do motivo que levou ao abandono e às várias perdas de vínculos, o sujeito se vê afetado, exigindo dele a adaptação ao novo contexto, impactando em seu conhecimento de mundo, bem como na busca de novos significados. Esta realidade perpassa todas as crianças que incidem pelo acolhimento, seja ele por pouco ou muito tempo, mantendo ou não vínculo familiar. Nessa trajetória, ocorrem diversas mudanças, desde o afastamento da família, até a inserção em um ambiente que requer o convívio coletivo - seja com outras crianças e adolescentes, seja com os funcionários plantonistas - no qual, muitas vezes, sua individualidade não é respeitada, o que pode gerar, em alguns casos, a perda de identidade, proporcionando sentimentos de abandono e rejeição.

Para Tinoco e Franco (2011), uma das características encontradas em crianças acolhidas, quando comparadas com crianças da mesma faixa etária, são reações de choro, raiva, angústia, ansiedade, somatização, baixo rendimento escolar, e, ainda, como apontado em alguns estudos, que esses comportamentos e sentimentos são expressões diante das perdas vividas e precisam ser acolhidas e entendidas, ademais, não se pode deixar de considerar as crianças que aparentemente não reagem a essas mudanças.

Muitas crianças e adolescentes que tiveram vivências significativas podem chegar à instituição mostrando-se independentes, mas, por outro lado, demonstram dificuldade em se vincular. Estes precisam de oportunidade para organizar as próprias experiências durante esse processo, que normalmente envolve vivências ruins, nas quais a criança, na maior parte das vezes, sente a sensação de perda de controle devido às mudanças, e isso ocasiona a falta de confiança no adulto responsável, por culpabilizá-los pela situação imposta a elas. Assim, essa ruptura abala seu sentimento de pertencimento, gerando uma grande insegurança para criança. Por outro lado, para ajudar a criança a elaborar sua história de perda, é essencial o desenvolvimento de um bom vínculo com um adulto e ambiente, permitindo que ela ressignifique sua situação e então recupere a segurança perante este novo ambiente. Durante esse processo, terá de se desapegar da figura perdida e se ligar a uma nova, mas isso só ocorrerá após estar minimamente ligada a alguém e segura (FERREIRA; ROJAS, 2013).

Nas pesquisas realizadas por Altoé, Silva e Pinheiro, (2011) foi elucidado que após o ECA, as novas instituições devem estar alinhadas aos demais equipamentos da rede de apoio socioassistencial, contudo, percebe-se que esses dispositivos que compõem a rede estão falhando em relação à garantia de direitos e cuidado das crianças e adolescentes atendidos. Esse déficit ocorre tanto na qualidade física do local como na atuação dos técnicos que muitas vezes não estão preparados para suas funções, bem como na preparação de medidas que suavizem a rotatividade de crianças que circulam entre famílias, serviços de acolhimento e a própria rua.

Essas mudanças necessárias devem ser planejadas de maneira adequada, preservando esses sujeitos, como, por exemplo, com atendimentos feitos na própria cidade ou até mesmo nos próprios bairros para possibilitar o cultivo dos laços afetivos com familiares e vizinhança. Ferreira, Littig e Vescovi (2014) apontam que crianças acolhidas apresentam efeito negativo sobre a institucionalização diante do desenvolvimento integral. Isso quer dizer que mesmo os serviços de acolhimento qualificados não são capazes de constituir um suporte amplo e eficiente para o suprimento de todas as necessidades, já que não podem substituir o convívio familiar. Desse modo, as possibilidades de existir relações estáveis para a construção de uma história são muito menores.

Segundo Hecht e Silva (2009), também devese considerar as crianças abandonadas e violentadas, que, através do acolhimento, podem construir para si perspectivas e possibilidades positivas nas instituições, mais do que no seio familiar. Nesse contexto, a instituição torna-se um meio possível para viabilidade de vida. Assim, o acolhimento pode vir a proporcionar, nesses casos, um sentimento de proteção através de uma experiência menos dolorosa e traumática, em espaços 
que permitirão um viável desenvolvimento integral, podendo gerar nelas capacidade de enfrentamento, desenvolvimento adaptativo e características de resiliência (DORIAN, 2003).

\section{Possibilidades de atuação do Psicólogo nos serviços de Acolhimento Institucional}

É importante reforçar que a instituição de acolhimento influencia bastante na construção psicossocial dos acolhidos, que envolverá um conjunto de relações com as quais a pessoa se depara ao longo da vida, em uma constante transformação.

Dentre os diversos profissionais que atuam nos serviços de acolhimento, o Psicólogo exerce um papel importante nestas instituições, pois o seu trabalho pode ser desempenhado em diversos contextos. Assim, tarefas realizadas nos serviços de acolhimento serão orientadas no sentido de considerar a existência das barreiras presentes neste cenário, exigindo uma flexibilidade de todos os profissionais que atuam nestas instituições (ALBERTO et al., 2008).

Outro ponto crucial é o papel do profissional de Psicologia relacionada às políticas públicas de assistência social voltadas às crianças e adolescentes. O Conselho Federal de Psicologia (2003), doravante CFP, orienta que o Psicólogo deve estar atento à proteção integral, atuando em rede de forma interdisciplinar, tendo grande importância social. Nesse sentido, Alberto et al. (2008) indicam que o Psicólogo, atrelado a outros profissionais da equipe técnica, funciona como um promotor de direitos, o que requer a sua participação nas políticas administrativas e na construção de espaços outros, fortalecendo debates e espaços coletivos, buscando assegurar a autonomia dos sujeitos, mesmo que institucionalizados.

Portanto, para Buffa, Teixeira e Rossetti-Ferreira (2010), o suporte prestado para o acolhido não deve se restringir às necessidades básicas como alimentação, cuidados com a saúde, entre outras, mas deve se estender ao amparo afetivo. Dessa forma, é preciso dar visibilidade a esses sujeitos (ORIONTE; SOUZA, 2005). O papel do psicólogo será de considerar a criança e adolescente como protagonistas da sua história.

Orionte e Souza (2005) apontam que, muitas vezes, nestas instituições, o que prevalece é o adulto impondo sua autoridade sobre essas crianças e adolescentes, desconsiderando o que é mais importante para elas. Assim, essa invisibilidade gera o impedimento destas de serem agentes ativos em sua própria vida, já que são submetidas, unicamente, ao poder do adulto.

Essas crianças acolhidas passaram por situações de separação e abandono, o que pode vir a resultar em sensibilidade frente a situações que as remetam ao desamparo. $\mathrm{O}$ medo de novas perdas parece acompanhar dolorosamente essa criança. Nesse sentido, o psicólogo que trabalha nestas instituições precisa respeitar o tempo necessário de cada criança, na busca por constituir vínculos que permitam que esta estabeleça uma relação transferencial que irá caracterizar esses encontros (ROTONDARO, 2002).

Para Assis, Diniz e Souza (2018), a intervenção deve ser feita de maneira cuidadosa, pois ela poderá resgatar uma situação dolorosa de vulnerabilidade e risco. Durante seu trabalho, o profissional pode desempenhar através de atividades lúdicas, aspectos como motivação, autopercepção, disciplina e regras. Possibilita, também, diante de seu trabalho, que a criança expresse os seus sentimentos, diminuindo uma possível ansiedade ocasionada em razão do acolhimento. Além disso, o Psicólogo pode atuar suscitando discussões de temas pertinentes à faixa etária das crianças e adolescentes acolhidos.

O psicólogo, ademais, pode ajudar essa criança e adolescente a desenvolver suas habilidades sociais diante do convívio com os técnicos e com os outros acolhidos, reconhecendo e expressando de maneira adequada suas angústias, sofrimentos, entre outros, auxiliando-os a deliberar melhor seus problemas. Segundo Rotondaro (2002), é importante refletir sobre as consequências frente ao abandono familiar, podendo ocasionar em algumas crianças e adolescentes a resistência para se envolver com o processo psicoterápico, pois o medo em estabelecer vínculos poderá ser algo ameaçador.

Para Hecht e Silva (2009), a instituição deve ser pensada como um local em que os acolhidos podem construir os referenciais identificatórios positivos do ponto de vista da construção do sujeito, considerando que os monitores desempenham papel central de proteção e se tornam modelos, construindo e participando da sua rede de apoio social e afetiva. O que ratifica a ideia de que a identidade da criança, seja ela institucionalizada ou não, está em permanente construção através do contato com o outro.

É importante, durante esse trabalho, reunir educadores para pensar em propostas de ação em um desejo comum para trabalhar com essas crianças e adolescentes que compartilham da mesma experiência (ROTONDARO, 2002). Por isso, o papel do psicólogo é ajudá-los a lidar com o processo de institucionalização e seus desdobramentos. No trabalho junto à equipe, este profissional auxilia no manejo das atividades que são realizadas com as crianças e adolescentes no serviço de acolhimento através de recursos como dinâmicas de grupo que permitem enxergar de que forma se pode reinventar e resolver os problemas de diversas maneiras, possibilitando que ocorra um compartilhamento das suas vivências. Ajudá-los a compreender e vivenciar este seu novo mundo (ASSIS; DINIZ; SOUZA, 2018). 
Desta forma, ainda segundo estes autores, a atuação do psicólogo contribui para uma melhoria na qualidade de vida, proporcionando a conscientização de sua identidade psicossocial. Tal processo só se concretizará se for permitido fazer escolhas, vivenciar múltiplas experiências, testar suas habilidades, descobrir suas preferências, ou seja, viver com um certo nível de autonomia, melhorando sua qualidade de vida através do atendimento individualizado, grupal, familiar e com a equipe multidisciplinar. Nesse sentido, o psicólogo pode possibilitar às crianças e adolescentes acolhidos condições para desenvolverem recursos de enfrentamento à situação de institucionalização, amenizando os impactos negativos no seu desenvolvimento socioafetivo. Além disso, o psicólogo pode atuar de modo a contribuir na vivência da criança acolhida, tornando a instituição um lugar de infância.

\section{Considerações Finais}

$\mathrm{Na}$ medida em que se buscam as diversas relações que perpassam as crianças e adolescentes institucionalizadas, logo na historicização do acolhimento institucional no Brasil, desvela-se a construção política social que classificou a juventude pobre como "menor", com o intuito de ter o controle e vigilância sobre este público. No entanto, com a criação do ECA, ocorre a alteração desta nomenclatura e as crianças e adolescentes passam a ser considerados sujeitos de direitos e deveres.

Além disso, com esta legislação, torna-se inadmissível utilizar a situação socioeconômica como motivo do acolhimento institucional, contudo, têmse a naturalização da família pobre como negligente para fomentar o processo de institucionalização. Nesse sentido, percebe-se o lugar que os serviços de acolhimento ocupam na defasagem da rede de garantia de direitos que deveria ser assegurada pelo Estado, portanto, nota-se a manutenção do processo de individualização de questões de cunho social, uma vez que o rompimento de vínculos se dá no momento em que a criança se encontra em situação de risco. No entanto, verificou-se que essa situação, geralmente, é atravessada pela pobreza.

Diante da destituição do poder familiar e da nova realidade marcada pela transitoriedade dentro dos serviços de acolhimento, foi elucidado que tais instituições devem ter um modo de funcionamento que garanta a proteção e o acolhimento das crianças e adolescentes de forma minimizar os impactos negativos adquiridos ao longo do processo de desvinculamento, bem como das vivências de violência que sofreram. Entretanto, foi localizado um tensionamento entre o que é preconizado e o que de fato acontece. Em contrapartida, também observou-se que os serviços de acolhimento, mesmo apresentando o caráter de provisoriedade estipulado pelo Art. 101 do ECA, podem se configurar como um espaço propício ao bom desenvolvimento do sujeito, investindo nas potencialidades das crianças e adolescentes, transformando-os em protagonistas de suas vivências, desde que tal ambiente seja acolhedor e personalizado.

Evidencia-se, com isso, a importância da contribuição da Psicologia nos serviços de acolhimento atuando de modo a enfrentar os diversos desafios inerentes a esses espaços, levando em consideração as relações de poder e características da instituição, além das particularidades das crianças e adolescentes acolhidas. Nesse sentido, cabe ao psicólogo utilizar de seus aparatos técnico-científicos no exercício de sua profissão e nos encontros diários em que são tecidas as problemáticas, a fim de se implicar na garantia dos direitos e proteção das crianças e adolescentes, sendo que esta perspectiva configura a dimensão política de sua atuação, uma vez que requer do profissional um compromisso social, na (re)construção contínua de suas práticas em defesa desses direitos, além de exigir a ampliação do seu olhar sob o Sistema de Garantias de Direitos e da Rede de Atendimento, com o intuito de promover, de fato, a autonomia dos sujeitos, isto é, fomentar os direitos humanos através de ações integrais, visando, inclusive, a transformação social.

Ademais, é reafirmada a importância do psicólogo na ressignificação de experiências, permitindo às crianças e adolescentes em situação de acolhimento um melhor entendimento, e, até mesmo, uma reconciliação com suas histórias, na construção de possibilidades futuras.

\section{Referências}

ALBERTO, Maria de Fátima Pereira et al. O Papel do Psicólogo e das Entidades Junto a Crianças e Adolescentes em Situação de Risco. Psicologia ciência e profissão, v. 28, n. 3, p. 558-573, 2008. Disponível em: http://pepsic.bvsalud. org/scielo.php?script $=$ sci arttext\&pid $=$ S1414-98932008000300010. Acesso em: 02 fev. 2020

ALMEIDA, Tatiana Lima de. História da institucionalização de crianças e adolescentes no brasil. Revista Santa Rita, n. 15, Junho, 2013. Disponível em: $\quad$ https://santarita.br/wp-content/uploads/2019/05/revistasrita-15. pdf\#page=20. Acesso em: 10 mar. 2020.

ALTOÉ, Sônia. Introdução. In: Menores em tempo de maioridade: do internato-prisão à vida social [online]. Rio de Janeiro: Centro Edelstein de Pesquisas Sociais, p. 5-7, 2009.

ALTOÉ, Sônia; SILVA, Magali; PINHEIRO, Bruna Soares. A Inconstância dos Laços Afetivos na Vida das Crianças e Adolescentes Abrigados. Psicologia política, v. 11, n. 21, janeiro- junho, p. 109-122, 2011. Disponível em: http://pepsic.bvsalud.org/scielo.php?script=sci_arttext\&pid=S1519549X2011000100009. Acesso em: 28 mar. 2020.

ARANTES, Esther Maria de Magalhães. Direitos da criança e do adolescente: um debate necessário. Psicol. clin, Rio de Janeiro , v. 24, n. 1, p. 45-56, 2012. Disponível em: http://www.scielo.br/scielo.php?script=sci arttext\&pid=S0103-56652012000100004\&lng=en\&nrm=iso. Acesso em: $0 \overline{9}$ mar. 2020.

ASSIS, Márcia Oliveira; DINIZ, Isabel Aparecida; SOUZA, Mayra Ferreira Silva de. Crianças Institucionalizadas: um olhar para o desenvolvimento 
socioafetivo. Revista da graduação em psicologia da PUC Minas, v. 3, n. 5, janeiro- junho, 2018. Disponível em: http://periodicos.pucminas.br/index. php/pretextos/article/view/15978. Acesso em: 28 mar. 2020.

BAPTISTA, Myrian Veras. Um olhar para a história. BAPTISTA, Myrian Veras (coord.). Abrigo: Comunidade de acolhida e socioeducação. São Paulo: In: Instituto Camargo Corrêa, 2006. (Coletânea abrigar; 1).

BRASIL. Estatuto da Criança e do Adolescente - ECA. Lei n ${ }^{\circ} 8.069$ de 13 de julho de 1990. Dispõe sobre o Estatuto da Criança e do Adolescente e dá outras providências. Brasília, 1990.

BUFFA, Carolina Gobato; TEIXEIRA, Sueli Cristina de Pauli; ROSSETTIFERREIRA, Maria Clotilde. Vivências de exclusão em crianças abrigadas. Psicologia: Teoria e Prática. Ribeirão Preto, v. 12, n. 2, p.1734, 2010. Disponível em: http://pepsic.bvsalud.org/scielo.php?script=sci_ arttext\&pid=S1516-36872010000200003. Acesso em: 28 mar. 2020.

COIMBRA, Cecília Maria Bouças; AYRES, Lygia Santa Maria; NASCIMENTO, Maria Lívia. Construindo uma psicologia no judiciário. In: COIMBRA, Cecília Maria Bouças; AYRES, Lygia Santa Maria; NASCIMENTO, Maria Lívia (Orgs.). Pivetes encontros entre a psicologia e o judiciário. Curitiba: Juruá, p.25-38, 2008.

CONSELHO FEDERAL DE PSICOLOGIA. Relatório do II Seminário Nacional de Psicologia e Políticas Públicas. Políticas Públicas, Psicologia e Protagonismo Social. João Pessoa: Conselho Federal de Psicologia, 2003.

DAROS, Thuinie Medeiros Vilela; PALUDO, Karine Inês. A institucionalização da Infância a partir dos aspectos históricos, políticos e pedagógicos. In: Seminário de pesquisa em educação da região sul. 9., 2012, Paraná. Anais. Paraná, p.1-15, 2012. Disponível em: http://www.ucs. br/etc/conferencias/index.php/anpedsul/9anpedsul/paper/viewFile/596/307. Acesso em: 02 fev. 2020.

DORIAN, Mônica Arpini. Repensando a Perspectiva Institucional e a Intervenção em Abrigos para Crianças e Adolescentes. Psicol. cienc. Prof, v. 23, n.1, Brasília, Março, 2003. Disponível em: http://www.scielo.br/scielo. php?pid=S1414-98932003000100010\&script=sci_arttext. Acesso em: 29 mar. 2020.

FERREIRA, Lúcia; BITTENCOURT, Sávio. Direito à Convivência Familiar de Crianças Abrigadas: o papel do Ministério Público. Revista Em Pauta, v. 6, n. 23, 2009. Disponível em: https://www.epublicacoes.uerj.br/index.php/ revistaempauta/article/view/451. Acesso em: 15 mar. 2020.

FERREIRA, Vanda Valle de Figueiredo; LITTIG, Patricia Mattos Caldeira Brant; VESCOVI, Renata Goltara Liboni. Crianças e adolescentes abrigados: perspectiva de futuro após situação de rua. Psicologia e sociedade, Vila Velha, v. 26, n. 1, p. 165-174, 2014. Disponível em: http://www.scielo.br/ scielo.php?script $=$ sci_arttext\&pid=S0102-71822014000100018. Acesso em: 14 mar. 2020

FERREIRA, Franchys Marizethe Nascimento Santana; ROJAS, Jucimara Silva. Aspectos lúdicos contribuindo no resgate da autoestima e na inclusão da criança abrigada. XI Congresso Nacional de Educação EDUCERE. II Seminário internacional de representações sociais, subjetividade e educação SIRSSE. IV Seminário internacional sobre profissionalização docente SIPD/ CÁTEDRA UNESCO. Anais. Pontifícia Universidade Católica do Paraná. Curitiba, 2013.

FRANÇA, Fátima. Reflexões sobre Psicologia Jurídica e seu panorama no Brasil. Psicologia: Teoria e Prática, v. 6, n. 1, p. 73-80, 2004. Disponível em: http://pepsic.bvsalud.org/pdf/ptp/v6n1/v6n1a06.pdf. Acesso em: 20 jan. 2020

GUARÁ, Isa Maria Ferreira Rosa. Abrigo: comunidade de acolhida e socioeducação. BAPTISTA, Myrian Veras (coord.). Abrigo: Comunidade de acolhida e socioeducação. São Paulo: In: Instituto Camargo Corrêa, 2006. (Coletânea abrigar; 1).

GULASSA, Maria Lucia Carr Ribeiro; LOPEZ, Imaculada. Imaginar para encontrar a realidade: reflexões e propostas para trabalho com jovens nos abrigos/ [coordenação da publicação Maria Lucia Carr Ribeiro Gulassa]. São Paulo: Associação Fazendo História: NECA - Associação dos Pesquisadores de Núcleos de Estudos e Pesquisas sobre a Criança e o Adolescente, 2010. (Coleção abrigos em movimento).

HECHT, Bruna; SILVA, Rebeca Fabricio Pereira da. Crianças institucionalizadas: a construção psíquica a partir da privação do vínculo materno. Psicologia.com.pt. Porto Alegre, 2009. Disponível em: https:// www.psicologia.pt/artigos/textos/TL0199.pdf. Acesso em: 20 fev. 2020.
MARINO, Adriana Simões. Do infans ao "menor" à concepção de criança e adolescente como sujeitos de direitos. Mnemosine, Rio de Janeiro, v. 9, n. 1, p. $54-79,2013$. Disponível em: https://www.e-publicacoes.uerj.br/index. php/mnemosine/article/viewFile/41527/pdf_274. Acesso em: 12 mar. 2020.

NASCIMENTO, Maria Livia do. Abrigo, pobreza e negligencia: percursos de judicialização. Psicologia e Sociedade, Belo Horizonte, v.24 (n.spe.), p. 39-44, 2012. Disponível em: http://www.scielo.br/scielo.php?script=sci arttext\&pid=S0102-71822012000400007. Acesso em: 20 mar. 2020.

NASCIMENTO, Maria Lívia; ROTENBERG, Alessandra; COSTA, Daniella Harth. Abrigo, pobreza e negligência: uma construção subjetiva. In: LEMOS, Flávia Cristina Silveira; e outros (Org.). Crianças, adolescentes e jovens: políticas inventivas transversalizantes. Curitiba: PR: CRV, p. 167185,2015

OLIVEIRA, Thiago Rosa Assis de; SILVA, Roberta Barbosa da. Práticas de Saber-Poder entre Pobreza e Negligência que se Configuram na Institucionalização da Infância. Revista Mosaico. v. 10, n. 25, março, Vassouras, 2019. Disponível em: http://editora.universidadedevassouras. edu.br/index.php/RM/article/view/1796. Acesso em: 28 mar. 2020.

ORIONTE, Ivana; SOUZA, Sônia Margarida Gomes. O significado do abandono para crianças institucionalizadas. Psicologia em Revista, Belo Horizonte, v. 11, n. 17, junho, p. 29 - 46, 2005. Disponível em: http://pepsic.bvsalud.org/scielo.php?script $=$ sci arttext\&pid=S167711682005000100003. Acesso em: 24 mar. 2020.

PALAGANA, Isilda Campaner. Desenvolvimento e aprendizagem em Piaget e Vygotsky: a relevância do social. 3. ed. São Paulo: Summus. 2001.

PINHEIRO, Ângela. Criança e adolescente no Brasil: por que o abismo entre a lei e a realidade. Fortaleza: Editora UFC, 2006.

RIZZINI, Irene; RIZZINI, Irma. Focalizando a história recente: panorama e desafios. In: RIZZINI, Irene; RIZZINI, Irma. A institucionalização de crianças no Brasil. Rio de Janeiro: Ed. PUC-Rio; São Paulo: Loyola, 2004. p. 43-59. [E-Book].

ROTONDARO, Daniela Pacheco. Os desafios constantes de uma psicóloga no abrigo. Psicol. cienc. Prof, v. 22, n. 3, setembro, Brasília, 2002. Disponível em: http://www.scielo.br/scielo.php?pid=S1414$98932002000300003 \&$ script=sci abstract\&tlng=pt. Acesso em: 28 fev. 2020.

SANTOS, Ana Maria Augusta. Acolhimento institucional de crianças e adolescentes: mudanças na história brasileira. In: SIMPÓSIO MINEIRO DE ASSISTENTES SOCIAIS, Belo Horizonte, 3, 2013. Anais. Belo Horizonte: CRESS 6 ${ }^{\text {a }}$ Região, 2013.

SANTOS, Érika Piedade da Silva. (Des) construindo a 'menoridade': uma análise crítica sobre o papel da Psicologia na produção da categoria "menor". In: GONÇALVES, Hebe Signorini; BRANDÃO, Eduardo Ponte (Orgs.). Psicologia Jurídica no Brasil. Rio de Janeiro: NAU Ed, p. 205- 248, 2004.

SOUZA, Michele Maria Brito da Ponte. Pobreza e Acolhimento Institucional de Crianças e Adolescentes na Cidade de Belém. Dissertação. (Mestrado em Segurança Pública). Programa de Pós-Graduação em Segurança Pública, Instituto de Filosofia e Ciências Humanas, Universidade Federal do Pará, Belém-PA, 2018

TINOCO, Valéria; FRANCO, Maria Helena Pereira. O luto em instituições de abrigamento de crianças. Estudos de Psicologia, Campinas, v. 28, n. 4, outubro-dezembro, p.427-434, 2011. Disponível em: http://www.scielo.br/ scielo.php?script $=$ sci arttext\&pid $=$ S0103-166X2011000400003. Acesso em: 03 fev. 2020. 